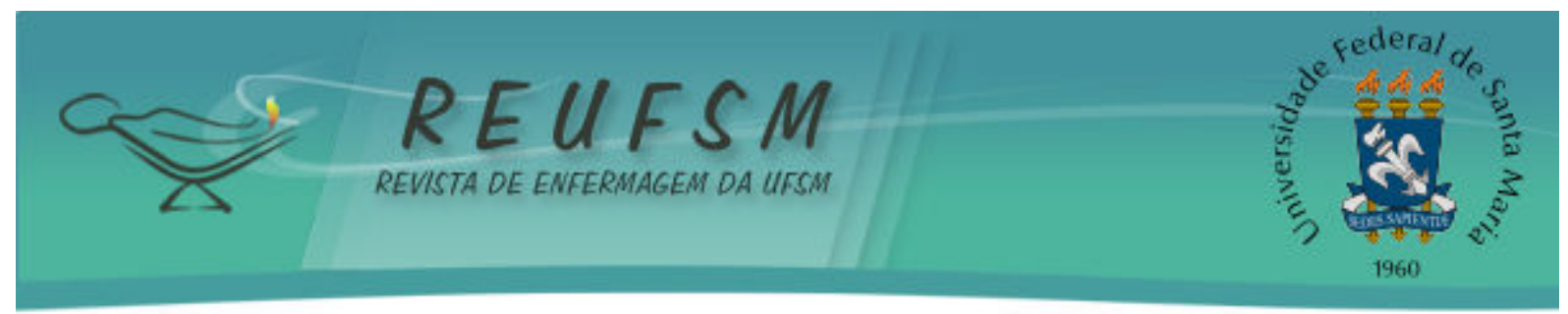

ARTIGO ORIGINAL

\title{
PARTICIPAÇÃO MASCULINA NO PLANEJAMENTO FAMILIAR E SEUS FATORES INTERVENIENTES
}

\author{
MALE PARTICIPATION IN FAMILY PLANNING AND ITS INFLUENCE FACTORS \\ PARTICIPACIÓN MASCULINA EN LA PLANIFICACIÓN FAMILIARY SUS FACTORES DE \\ INFLUENCIA
}

Doi: $10.5902 / 217976929998$

Ana Cláudia Brito de Morais ${ }^{1}$
Atayane Gomes Ferreira
Kele Leandro Almeida
Glauberto da Silva Quirino $^{4}$

RESUMO: Objetivo: identificar as formas de participação masculina no processo de planejamento familiar, bem como os fatores intervenientes nessa participação, conhecer os saberes masculinos acerca do método utilizado pelo casal e descrever como acontece o processo de negociação na escolha do método. Método: pesquisa exploratória, com abordagem qualitativa, com 16 homens. Utilizou-se um formulário e uma entrevista semiestruturada, sendo os dados organizados pelo Método do Discurso do Sujeito Coletivo. Resultados: os homens participavam do planejamento familiar, apoiando de forma logística suas companheiras. A responsabilidade sobre a contracepção era feminina, devido a pouca disponibilidade de tempo dos parceiros. Estes conheciam a camisinha e o contraceptivo oral hormonal, contudo pouco dialogavam sobre a negociação do uso do método contraceptivo. Considerações finais: o planejamento familiar, ainda, ocorre de forma unilateral e pautado na hierarquia de gênero, que impõe sobre as mulheres o encargo da responsabilidade, simbólica e corporal, de contracepção.

Descritores: Planejamento familiar; Anticoncepção; Saúde reprodutiva; Enfermagem.

ABSTRACT: ABSTRACT: Aims: to identify the forms of male participation in the family planning process, as well as the factors involved in their participation, to comprehend the men's knowledge about the method used by the couple and to describe how the process of negotiation happens when choosing the method. Method: exploratory research with qualitative approach carried out with 16 men. We used a form and semi-structured interview as instruments for data collection, which were organized by the Discourse of the Collective Subject Method. Results: the men participated in family planning as logistical support to their partners. The responsibility on contraception was women's, due to limited time availability of partners. They knew about condoms and oral contraceptive hormones, however discussed little about trading the use of contraception. Final remarks: family planning still happens unilaterally and guided by the gender hierarchy that imposes upon women the burden of symbolic and physical responsibility of contraception.

Descriptors: Family planning; Contraception; Reproductive health; Nursing.

\footnotetext{
1 Enfermeira. Universidade Regional do Cariri (URCA). Grupo de Pesquisa em Saúde Coletiva (GRUPESC/CNPq/URCA). Crato, Ceará, Brasil. E-mail: aninha_cbm_@hotmail.com

Enfermeira. Universidade Regional do Cariri (URCA). Grupo de Pesquisa em Saúde Coletiva (GRUPESC/CNPq/URCA). Crato, Ceará, Brasil. E-mail: atayanegf@yahoo.com.br

3 Enfermeira. Universidade Regional do Cariri (URCA). Grupo de Pesquisa em Saúde Coletiva (GRUPESC/CNPq/URCA). Crato, Ceará, Brasil. E-mail: kele.l.a@hotmail.com

4 Enfermeiro. Doutor em Educação em Ciências: Química da Vida e Saúde (UFSM). Professor Adjunto do Departamento de Enfermagem da Universidade Regional do Cariri (URCA). Grupo de Pesquisa em Saúde Coletiva (GRUPESC/CNPq/URCA). Crato, Ceará, Brasil. E-mail: glauberto.quirino@urca.br
} 


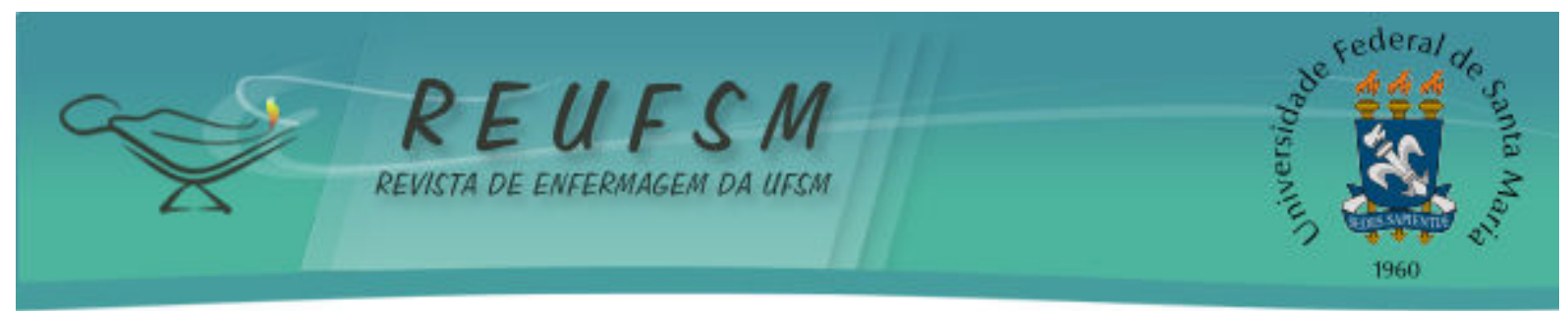

RESUMEN: Objetivos: identificar las formas de participación masculina en el proceso de planificación familiar, los factores que intervienen, conocer los saberes masculinos acerca del método utilizado por la pareja y describir cómo funciona el proceso de negociación en la elección del método. Método: investigación exploratoria, cualitativa, con 16 hombres. Se utilizó formulario y entrevista semi-estructurada, siendo los datos organizados por el método del Discurso del Sujeto Colectivo. Resultados: los hombres participaron en la planificación familiar, por el apoyo logístico a sus compañeras. La responsabilidad de la anticoncepción era femenina, debido a la escasa disponibilidad de tiempo de los compañeros. Ellos conocían los preservativos y anticonceptivos orales hormonales, sin embargo, poco dialogaron sobre la negoción del uso de anticonceptivos. Observaciones finales: la planificación familiar aun ocurre de manera unilateral, basada en la jerarquía de género que impone a las mujeres la responsabilidad, simbólica y corporal, de la anticoncepción.

Descriptores: Planificación familiar; Anticoncepción; Salud reproductiva; Enfermería.

\section{INTRODUÇÃO}

O planejamento familiar é considerado um direito ao acesso à informação, à assistência especializada e aos recursos que permitam optar livre e conscientemente por ter ou não ter filhos, o número, o espaçamento entre eles e a escolha do método anticoncepcional mais adequado de forma livre sem discriminação, coerção ou violência. ${ }^{1}$

Entretanto, o reflexo da práxis diária dos serviços de saúde ressente-se da participação masculina no processo de planejamento familiar. Na atualidade brasileira, o que se observa é que a mulher responsabiliza-se pela implementação de métodos contraceptivos. ${ }^{2}$

Recentemente, a Política de Atenção à Saúde do Homem no Brasil aduziu um subitem relativo aos direitos sexuais e reprodutivos, em que enfatizou a necessidade da implementação desses direitos para os homens. 0 documento reafirma a importância da presença masculina no processo reprodutivo, sendo imperativo a restrição da responsabilidade sobre as práticas contraceptivas às mulheres. No entanto, o processo de implementação desta política não foi resultado da luta dos movimentos sociais, a exemplo do que aconteceu com a política voltada para as mulheres. Nesse sentido, aponta-se como principal motivo para essa consecução, os interesses de determinadas corporações profissionais. ${ }^{3}$

A desigualdade quanto à responsabilidade do homem e da mulher no controle da fecundidade fica evidenciada pela quantidade de métodos contraceptivos destinados às mulheres e aos homens, responsabilidade do processo reprodutivo atribuída às mulheres e pelo preconceito masculino em relação a determinados métodos contraceptivos, como a vasectomia. ${ }^{4}$

Pode-se afirmar que essa exiguidade deve-se a inúmeros fatores relacionados tanto ao serviço de saúde oferecido quanto ao próprio homem. Dentre esses fatores, tem-se a diminuta importância dada ao planejamento familiar, que permanece em segundo plano quando colocado defronte a outros serviços de assistência à mulher, pois, ainda, está organizado de forma a privilegiar o binômio materno-infantil e, quando o encaminhamento ao planejamento reprodutivo, favorece mulheres em atendimento ao pré-natal e ao pós-parto. ${ }^{5}$

Dessa forma, é primordial que as ações em saúde, voltem-se para a redução das diferenças de gênero na perspectiva de envolver o homem na saúde sexual e reprodutiva, não apenas no amparo financeiro, mas na troca de experiências, escolhas e utilização de métodos de contracepção e compartilhamento de responsabilidades com as mulheres.

Ressalte-se, portanto, que discutir sobre a participação masculina no planejamento familiar é abrangente, ultrapassando as questões relacionadas à opção pela 


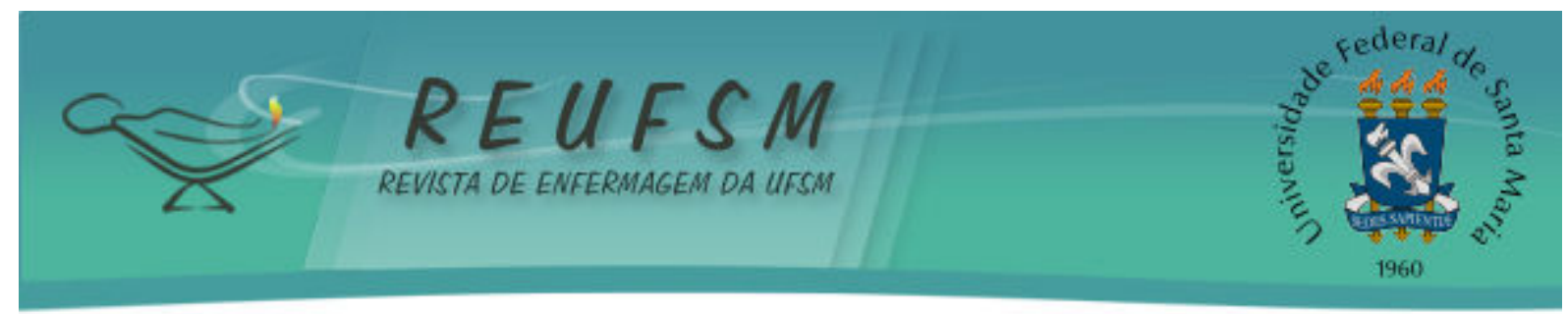

vasectomia ou uso do condom, pois exige abordagem das relações de gênero, considerando que os homens, também, possuem sentimentos, opiniões, cultura, religião e emoções. ${ }^{6}$

No sentido de contribuir para essa discussão, realizou-se o seguinte questionamento: de que forma os homens participam do processo de planejamento familiar e quais seus fatores intervenientes?

A partir dessa cogitação, este estudo objetivou identificar as formas de participação masculina no processo de planejamento familiar, os fatores intervenientes nessa participação, os saberes masculinos acerca do método utilizado pelo casal, bem como descrever como acontece o processo de negociação na escolha do método.

\section{MÉTODO}

Pesquisa exploratória, com abordagem qualitativa, ${ }^{7}$ desenvolvida no domicílio dos participantes e no Centro Microrregional de Excelência à Assistência Reprodutiva (CEMEAR), na cidade do Crato (CE), no período de novembro de 2010 a agosto de 2011.

Os sujeitos que fizeram parte desta pesquisa foram 16 homens. A totalidade dos sujeitos obedeceu à saturação teórica dos dados. Os critérios de inclusão foram: usuários do sexo masculino, cujas companheiras estivessem cadastradas no Programa de Planejamento Familiar do CEMEAR; residentes na cidade do Crato; casados civilmente ou por união consensual. Foram excluídos da pesquisa os homens que não estavam na cidade no período da coleta de dados e os menores de idade.

Este estudo ocorreu em dois momentos: identificação e escolha dos participantes diante do cadastro das companheiras no Programa de Planejamento Familiar no CEMEAR, onde foram obtidos os endereços, nas consultas ao caderno de registros do serviço e, no segundo momento, visitas domiciliares aos pré-selecionados, para explicitação dos objetivos da pesquisa e coleta de dados.

Para coleta de dados, foram utilizados como instrumentos: formulário com questões objetivas e subjetivas referentes à caracterização sociocultural dos sujeitos; entrevista semiestruturada que esteve voltada para as formas de participação dos homens no planejamento familiar, os fatores intervenientes do processo, os saberes sobre os métodos contraceptivos usados pelo casal e a influência das relações de poder na escolha de métodos contraceptivos.

Para a organização, apresentação e análise dos dados, utilizou-se o Método do Discurso do Sujeito Coletivo (DSC), técnica de construção do pensamento coletivo que visa revelar como as pessoas pensam, atribuem sentidos e manifestam posicionamentos sobre determinado assunto. Trata-se de um compartilhamento de ideias dentro de um grupo social. O DSC é um espelho coletivo; como se as pessoas se olhassem e, a partir daí, tomassem consciência de como são. ${ }^{8}$

De acordo com o método DSC, a informação contida no discurso deve ser analisada em uma leitura inicial e classificada por Expressões-chave (E-Ch) que representa as principais respostas para a questão de interesse. A partir desta identificação, estas E-Ch são agrupadas, compondo um conjunto de pensamentos ou ideias que a coletividade expressou sobre a pergunta formulada. Uma nova leitura e análise das $\mathrm{E}-\mathrm{Ch}$ permite a identificação de suas Ideias Centrais (IC), também reunidas por semelhança, formando os discursos coletivos. Os textos originais são assim decompostos por suas expressões (E-Ch) de maior interesse de análise, e, em seguida, categorizados por suas afinidades de sentido (ICs) e reunificados em um discurso construído em primeira pessoa do singular, que expressa o pensamento coletivo sobre o tema. ${ }^{8}$

Este estudo foi realizado conforme a Resolução n ${ }^{\circ}$. 466/2012 do Conselho Nacional de Saúde a qual discorre sobre as diretrizes e normas regulamentadoras de pesquisa 


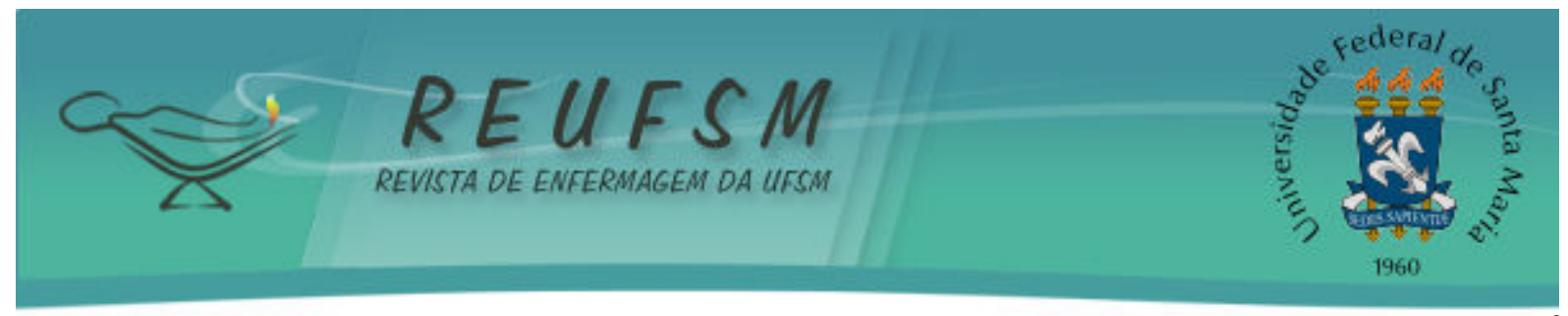

envolvendo seres humanos, em observação a princípios éticos para com os participantes. ${ }^{9}$ O projeto foi encaminhado ao Comitê de Ética em Pesquisa da Universidade Regional do Cariri - URCA, sendo aprovado segundo parecer de número 42/2010. Ressalte-se, ainda, que os participantes da pesquisa leram e assinaram o Termo de Consentimento Livre e Esclarecido.

\section{RESULTADOS E DISCUSSÃO}

Os homens entrevistados encontravam-se na faixa etária compreendida entre 18 e 47 anos, idade caracterizada por fertilidade e capacidade reprodutiva satisfatória. ${ }^{6} \mathrm{~A}$ maioria era católico, concluiu o ensino médio ou encontrava-se cursando. Trabalhavam nos horários matutino e vespertino.

Diante dos dados, inferiu-se que o fato de não existir um horário diurno disponível para a visita à unidade de saúde poderia dificultar a participação masculina no Planejamento Familiar (PF) e, consequentemente, reduzida presença dos homens no planejamento.

A indisponibilidade de tempo para buscar por serviços de saúde, a ausência de serviços e de programas especializados para pessoas do sexo masculino, a timidez quanto à exposição a um desconhecido e o medo da descoberta de doença grave são aspectos de extrema relevância na composição do quadro da saúde do homem na atenção primária. ${ }^{10}$

\section{Participação masculina no planejamento familiar}

As formas de participação masculina no planejamento familiar foram identificadas a partir do método DSC, cujos discursos foram construídos com as respostas dos participantes, acerca da pergunta relacionada à forma de participação no planejamento familiar. Foram encontradas quatro ideias centrais e, por conseguinte, surgiram quatro DSC.

\section{DSC/IC1 - Apoio: buscar a medicação e lembrar a mulher de tomar o anticoncepcional}

A IC1 foi a mais frequente entre as respostas dos homens participantes, que mencionaram que a participação era limitada ao apoio do método utilizado pela companheira e auxílio nas tarefas de ir à unidade para pegar o contraceptivo e de lembrála de usá-lo.

Ajudo apoiando e pegando remédio, para poder evitar. Lembro sempre ela a hora de tomar os comprimidos. Concordo com o que ela decidir. (DSC 1)

Os homens revelaram que a responsabilidade da manutenção do planejamento familiar era, principalmente, da companheira. Para estes, sua função era apenas de apoiar a decisão, a fim de evitar consequências do uso inadequado do contraceptivo. Apesar de identificada a presença dos homens na unidade de saúde, esta era secundária à função que era das companheiras.

Estudo realizado em São Gonçalo do Amarante, Ceará, entre os 171 prontuários de um serviço de PF de duas microáreas, selecionados aleatoriamente, $158(92,4 \%)$ eram de usuárias do gênero feminino e apenas $13(7,6 \%)$ do gênero masculino, confirmando, assim, a maior responsabilidade feminina no controle reprodutivo. ${ }^{11}$ Esses dados revelaram a dificuldade de participação direta do homem no PF. 


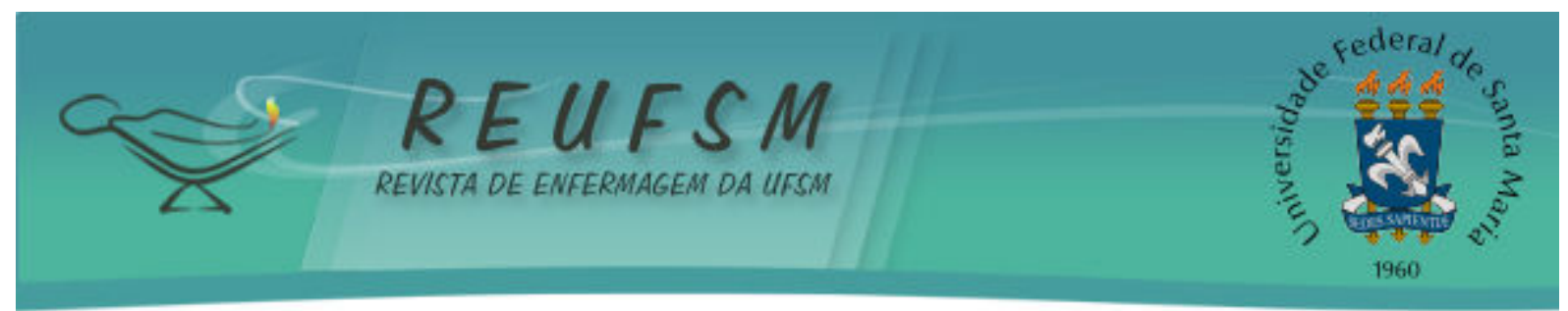

Aspecto importante acerca do PF refere-se à centralização na figura feminina. $\mathrm{Na}$ maioria das vezes, a mulher participa sozinha das orientações oferecidas pelas unidades de saúde a respeito do planejamento familiar. Sendo a responsável pela escolha do contraceptivo, além de que assume a responsabilidade pela decisão da quantidade de filhos. $^{12}$

\section{DSC/IC2 - Apoio na compra dos métodos}

A IC2 revelou a ajuda financeira dos homens para que a companheira garantisse a utilização dos métodos contraceptivos:

Compro comprimido ou camisinha quando não tem ou quando ela não vai ao posto. (DSC 2)

A contribuição financeira marca, historicamente, a construção social de gênero, em que o homem tem a função de manter os recursos materiais necessários à subsistência da família e à mulher cabe a responsabilidade pela casa, pelos filhos e pelas demais funções referentes à organização do lar, demarcando o uso do espaço público e privado, masculino e feminino, respectivamente.

Consequentemente, atribuí-se a contracepção como exclusividade feminina, tendo os homens um papel secundário nos processos reprodutivos. ${ }^{13}$

\section{DSC/IC3 - Uso da camisinha}

As respostas que formaram esse discurso foram de homens que usavam a camisinha como método exclusivo ou complementar utilizado pelo casal.

Eu uso a camisinha. (DSC 3)

Os homens que relataram que o casal fazia uso exclusivo da camisinha como método anticoncepcional, declararam que a escolha era realizada como última opção, uma vez que as companheiras não desejavam e/ou não podiam utilizar métodos hormonais, devido às reações adversas ou efeitos colaterais. Além disso, os homens que utilizavam de forma complementar, corroboraram que era devido à desconfiança ou uso inadequado do método utilizado pela companheira.

Julga-se pertinente valorizar que o uso do condom foi citado como última opção do casal. Inferiu-se, portanto, a resistência por parte do homem ou do casal em utilizar esse método.

O preservativo masculino é um dos mais antigos métodos contraceptivos, contudo a aceitabilidade entre os homens ainda é pequena, porém negociável e são as mulheres que procuram pelos serviços de saúde para recebê-lo. ${ }^{14}$

\section{DSC/IC4 - Não existe ajuda}

A IC 4 foi a menos frequente. 0 relato embora radical mostrou a realidade ainda existente que direciona toda responsabilidade da contracepção à mulher, uma vez que todo processo de concepção acontece em seu corpo e, por isso, estas devem ter as maiores preocupações. 


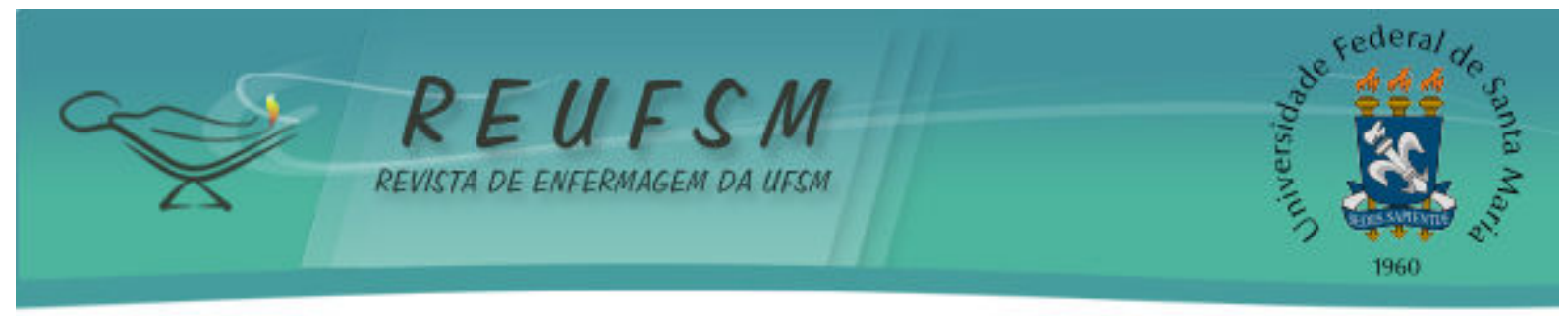

Eu não ajudo é de jeito nenhum. Ela toma comprimido anticoncepcional. (DSC 4)

O planejamento familiar é um método de prevenção e de intervenção na saúde da família, portanto deve considerar a unidade familiar e não apenas a mulher. No entanto, o homem ainda parece desconhecer tal conceito. ${ }^{12}$

Consolidando os achados da participação masculina no PF, evidenciou-se que os três primeiros discursos, gerados a partir das falas, apresentaram uma forma de ajuda demonstrada, predominantemente, através do apoio. Aos homens ainda foi questionado se seria suficiente essa forma de ajuda. Encontrou-se que a maioria deles mostrou-se satisfeita, ademais considerou suficiente a forma de participação, pois a mulher ainda não havia engravidado. Pressupõe-se, a partir desses achados, que o homem preocupa-se com a limitação do número de filhos, desconsiderando o fato de o método ser agradável ou não para o casal.

Pequena parcela dos homens relatou ser insuficiente o apoio como forma de ajuda. Inúmeras reclamações que, ocasionalmente, aparecem como queixas pelas mulheres nos usos dos métodos, podem estar motivando os homens a reconhecer tal fato. Apesar disso, estes não reconheciam alternativa, senão a utilização de um método feminino, devido à limitação de métodos contraceptivos masculinos e as experiências negativas com esses métodos.

\section{Fatores intervenientes na participação masculina no PF}

Os homens relataram que a iniciativa de procurar pelo Programa de Planejamento Familiar foi de suas companheiras e os fatores que dificultavam a sua inserção estiveram relacionados a pouca disponibilidade de tempo, sendo o serviço procurado em decorrência da necessidade de contracepção.

DSC/IC1 - Responsabilidade da mulher em virtude da pouca disponibilidade de tempo do companheiro

A IC 1 referiu o tempo como fator que dificultava a participação do homem no planejamento familiar, surgindo assim o DSC 1 que pretendeu elucidar o afastamento do homem em relação às questões de PF e, consequentemente, lançando sobre as mulheres a responsabilidade deste:

Foi minha mulher. A agente de saúde veio aqui, fez o cadastro, mas a iniciativa foi dela, ela foi buscar e ficou fazendo as consultas lá no posto. Eu não vou por falta de tempo, passo o dia trabalhando, meu tempo é muito corrido, eu não tenho tempo de fazer quase nada. (DSC 1)

Aponta-se que os empecilhos práticos dados pelos homens, como falta de tempo, não justificam o papel limitado que estes desempenham no controle da fecundidade, uma vez que as mulheres também praticam uma variedade de atividades domésticas, familiares e, muitas vezes, profissionais, e mesmo assim ainda são responsáveis pela contracepção. ${ }^{14}$

\section{DSC/IC2 - Responsabilidade da mulher para prevenir a gravidez}

A IC 2 identificou a mulher como responsável pela prevenção da gravidez: 


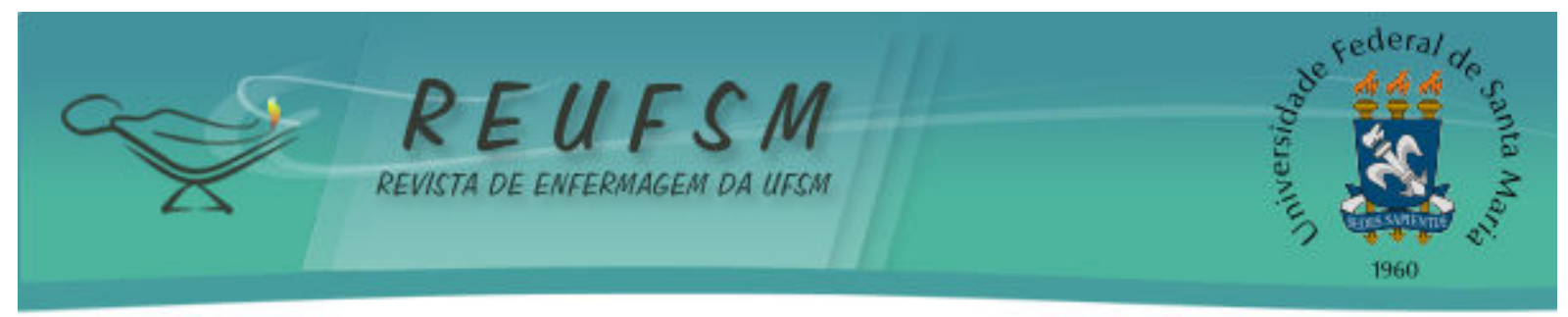

Quem procurou o posto foi minha esposa. Porque a gente tem previsão de filhos, mas não agora, nós queremos passar um tempo sem ter outro [filho], porque dá muito trabalho também. (DSC 2)

Nesse discurso, é patente que a mulher é a responsável por ir até o posto, além de tomar todas as medidas para evitar a gravidez indesejada, ainda que a decisão seja tomada pelo casal.

A maior ocorrência de participação feminina no planejamento familiar pode estar associada à cultura patriarcal e biologia humana, pois quem engravida é a mulher e a ela, muitas vezes, é imposta a responsabilidade do controle de natalidade. ${ }^{15}$

\section{DSC/IC3 - Responsabilidade da mulher porque engravidou}

Nesta DSC, a responsabilidade é atribuída à mulher devido ao fato de regularmente visitar o posto em função de outras atividades relacionadas à saúde:

Foi minha mulher que procurou o posto porque ela estava grávida e tinha que ir fazer o pré-natal. (DSC 3)

Essa realidade vem mostrar as lacunas existentes no modelo de planejamento familiar, tendo em vista que o principal eixo de ação é o foco exclusivo na saúde da mulher e seu ciclo gestatório. ${ }^{12}$ Dessa forma, a unidade familiar não tem sido considerada e faz com que a estratégia de trazer o homem para o centro das discussões, principalmente nos grupos do PF, como orienta a proposta do programa, na prática, seja falha. ${ }^{16}$

Além disso, estimular a participação do parceiro sexual nas consultas de planejamento familiar e em atividades educativas pode contribuir sobremaneira para 0 processo de comunicação entre o casal. ${ }^{17}$

\section{Saberes acerca do método utilizado pelo casal}

No que diz respeito ao método utilizado pelo casal, $75 \%$ (12) dos participantes afirmaram estar em uso do anticoncepcional oral, $12 \%$ (2) relataram estar em uso do condom masculino e $12 \%$ (2) referiram estar em uso da associação de dois métodos: a camisinha, juntamente, com o método hormonal injetável ou anticoncepcional oral com a camisinha.

Em se tratando da escolha do método que será utilizado pelo casal, o resultado está de acordo com estudo sobre a temática, o qual evidenciou a preferência dos casais pelos métodos hormonais orais, sendo seguidos pelo uso do condom masculino, ambos superados apenas pela laqueadura tubária. ${ }^{18}$

Quando questionados sobre o conhecimento acerca do método utilizado pelo casal, a maioria dos informantes, cujas companheiras utilizavam o método hormonal oral, informou que se tratava de um hormônio que inibia a ovulação, que deve ser tomado diariamente, tendo um período de pausa para ocorrer a menstruação. No concernente ao condom masculino, todos os sujeitos que afirmaram estar em uso destes, relataram que se tratava de um método de barreira, impedindo a passagem do sêmen, prevenindo assim a gravidez e infecções sexualmente transmissíveis. E, em relação ao método hormonal injetável, os sujeitos, cujas companheiras estavam em uso desse método, referiram não ter conhecimentos sobre o mesmo. 


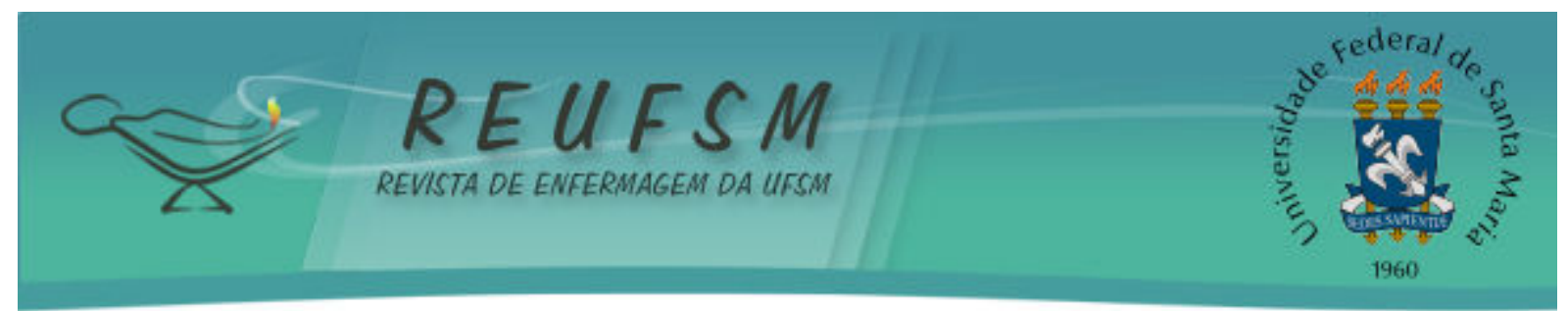

Um estudo mostra que os métodos mais conhecidos pelos homens são aqueles os quais eles participam diretamente ou então aqueles que reconhecem pela utilização de suas companheiras. ${ }^{19}$

Havia um conhecimento razoável, por parte dos sujeitos, sobre os métodos mais prevalentes no estudo. 0 achado talvez esteja relacionado ao fato de estes serem os métodos mais amplamente divulgados pela mídia e/ou pelos profissionais de saúde, assim como pela maior disponibilidade nos serviços de saúde.

Deve-se enfatizar a importância do saber masculino sobre os métodos contraceptivos, pois é preciso que compreenda a relevância de adquirir esse conhecimento, mesmo que quem use o método seja a mulher, optando assim, em comum acordo, pelo melhor método. Desta forma, ele estará contribuindo para um aumento da eficácia e continuidade do método. ${ }^{4}$

\section{Processo de negociação do casal na escolha do método contraceptivo}

Quando questionados sobre a escolha do método contraceptivo utilizado pelo casal, quase todos os participantes destacaram que a escolha foi da mulher. As mulheres assumiam para si o encargo da contracepção, em que ao optar sozinhas por métodos femininos estavam liberando seus companheiros da responsabilidade dessa tarefa. Nesse sentido, o controle da fecundidade ainda é considerado como uma função feminina. ${ }^{14}$

Em se tratando da concordância referente ao uso do método escolhido pelo casal, a maior parte dos homens relatou que concordavam com o método escolhido. Isso se deve ao fato de apresentarem eficácia na contracepção do casal, uma vez que os homens não desejavam ter mais filhos, bem como por não precisarem se preocupar em participar ativamente da contracepção.

Já a discordância foi justificada porque os homens desejavam mais filhos, enquanto a parceira não, e também por acharem que o contraceptivo utilizado, de alguma forma, seria prejudicial à companheira, e por isso intentavam trocar o método escolhido por outro menos prejudicial.

É essencial destacar o fortalecimento da ideia de que o homem tem papel importante na saúde reprodutiva do casal; de que o uso efetivo de contraceptivos e a satisfação com o método escolhido são, frequentemente, influenciados pelo homem; e de que ter o suporte do parceiro contribui para melhor uso de métodos femininos. ${ }^{4}$

Quando questionados se consideravam que a companheira concordava com o uso do contraceptivo escolhido, a maioria dos homens relatou que a parceira concordava. As mulheres aceitavam os métodos utilizados porque, em sua maioria, foram elas que o escolheram, muitas vezes, sem a contribuição do parceiro nessa decisão, atitude considerada de autonomia.

0 fato de as parceiras não concordarem com o método utilizado se deve a não satisfação com o uso de comprimidos, provavelmente em virtude das reações adversas, e por pretenderem a participação do homem na contracepção, de modo a dividir as responsabilidades.

Existem dois problemas que podem interferir no poder das mulheres de controlarem a fertilidade: a influência dos homens na escolha do método anticoncepcional e a negação deste em participar da anticoncepção. ${ }^{20}$

Os participantes foram questionados se existia algo que incomodava ou se tinham alguma dúvida sobre os métodos utilizados. Mais da metade relatou não ter nada que incomodasse a utilização do contraceptivo, embora uma parcela afirmou que o uso do método gerava algum tipo de desconforto ou dúvidas, além de causar alterações de humor na parceira. 


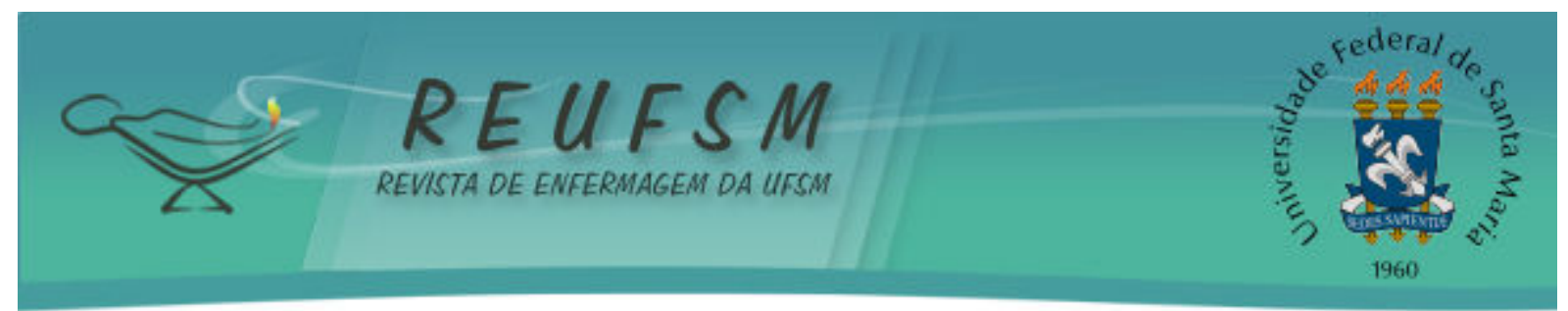

O fato de o método utilizado causar algum tipo de desconforto pode resultar no uso incorreto do contraceptivo e até a rejeição do mesmo. Se o casal não estiver informado sobre os métodos disponíveis, pode causar redução nas opções de utilização e afetar, efetivamente, a contracepção.

Quando questionados a respeito da existência de diálogo entre o casal sobre a troca do método utilizado, apenas um pouco mais da metade relatou que já ocorreu a conversa, entretanto, a substituição ainda não havia ocorrido porque houve discordância entre o casal. Por mais que a maioria dos homens relatasse que já havia algum tipo de diálogo sobre o assunto, evidenciou-se que a discussão não estava sendo produtiva, pois o casal não alcançava a concordância, o que poderia prejudicar a eficácia do método.

Parece oportuno afirmar que o diálogo entre o casal sobre o planejamento reprodutivo é realidade para parte das mulheres e homens envolvidos no processo.

Corroborando com esta assertiva, um estudo gaúcho sobre anticoncepção constatou que ainda existem muitas mulheres que não conversam com seus companheiros porque entendem que esse é um campo de decisão que lhe diz respeito, ou não o fazem porque o parceiro decide sozinho e impõe suas escolhas para a mulher, de forma pacífica ou violenta, culminando na decisão de uso de métodos femininos. ${ }^{20}$

Vale destacar, ainda, a importância da discussão entre o casal para igualdade de gênero, respeito mútuo e compartilhamento com os homens nessas responsabilidades que envolvem a vida a dois. ${ }^{21}$ Assim como serviços de saúde que incluam a participação masculina nas suas ações estratégicas. ${ }^{22}$

\section{CONSIDERAÇÕES FINAIS}

0 estudo realizado junto aos homens possibilitou o conhecimento das formas de participação masculina no planejamento familiar e seus fatores intervenientes.

Constatou-se que, em geral, os homens participavam por meio da oferta de apoio logístico às companheiras.

Ademais apontaram como fator de impedimento a falta de tempo, uma vez que por assumir atividades laborais extradomiciliares, os horários de disponibilidade eram incompatíveis ao funcionamento dos serviços de saúde, deslocando a responsabilidade de contracepção, principalmente, para a mulher.

Identificou-se uma lacuna de conhecimento sobre o programa de planejamento familiar pelos sujeitos participantes. Embora o saber não seja garantia de mudança na forma de participação masculina, aos sujeitos foram assegurados a ciência sobre direitos e deveres, possibilitando a ação de forma mais consciente e crítica na escolha pelo uso de qualquer que seja o método contraceptivo.

Aponta-se a pouca negociação entre os casais para a escolha e manutenção da utilização dos métodos contraceptivos, indicando que esta ocorre de forma unilateral e pautada na hierarquia de gênero, que impõe sobre as mulheres o encargo da responsabilidade, simbólica e corporal, de contracepção.

Sugere-se a capacitação e incentivo para mudança de paradigmas de profissionais que lidem diretamente com o planejamento familiar para sensibilizar a população masculina a participar de forma mais direta no planejamento das famílias, de modo a minimizar as dificuldades relacionadas às questões de gênero e envidar esforços na construção de um programa efetivo. Acredita-se ser relevante o desenvolvimento de estudos nesta temática, principalmente aqueles que relatem sobre os fatores que inibem a participação dos homens no planejamento familiar, produzindo assim reflexões na busca por superar essa problemática. 


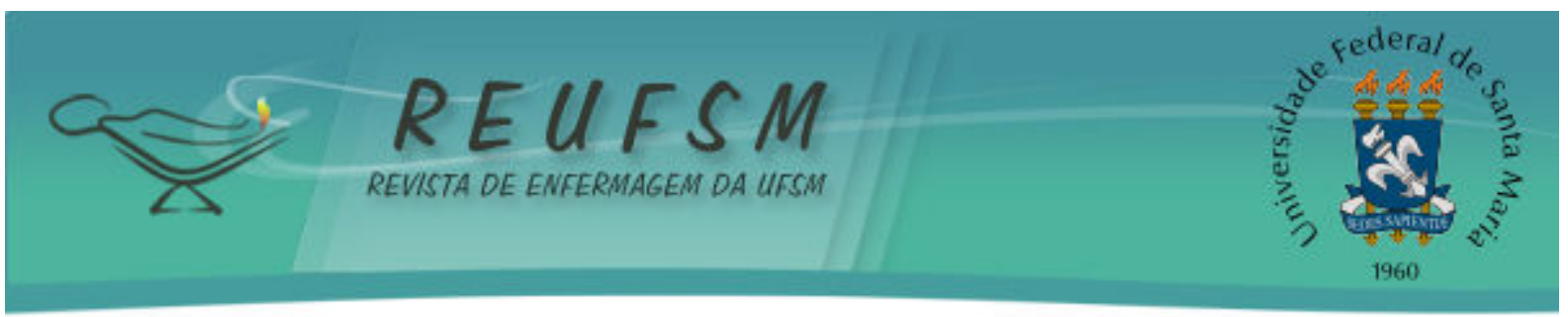

\section{REFERÊNCIAS}

1. Brasil. Lei $n^{\circ} 9.263$, de 12 de janeiro de 1996. Regula o $\$ 7^{\circ}$ do artigo 226 da Constituição Federal, que trata do planejamento familiar, estabelece penalidades e dá outras providências. Diário Oficial da União, Brasília; 1996 jan 15.

2. Nicolau AIO, Moraes MLC, Lima DJM, Aquino OS, Pinheiro AKB. História reprodutiva de mulheres laqueadas. Acta Paul Enferm. 2010;23(5):677-83.

3. Carrara S, Russo JA, Faro L. A política de atenção à saúde do homem no Brasil: os paradoxos da medicalização do corpo masculino. Rev Saúde Coletiva. 2009;19(3):659-78.

4. Dutra A, Pereira AL. A participação masculina em grupos educativos de contracepção: o olhar da enfermagem. Rev Pesq Cuid Fundam [Internet]. 2009 [acesso em $2011 \mathrm{abr}$ 28];1(2):360-71. Disponível

em: http://www.seer.unirio.br/index.php/cuidadofundamental/article/view/395/384.

5. Heilborn ML, Portella AP, Brandão ER, Cabral CS. Assistência em contracepção e planejamento reprodutivo na perspectiva de usuárias de três unidades do Sistema Único de Saúde no Estado do Rio de Janeiro, Brasil. Cad Saúde Pública. 2009;25 Supl 2:269-78.

6. Bezerra MS, Rodrigues DP. Representações sociais de homens sobre o planejamento familiar. Rev RENE. 2010;11(4):127-34.

7. Gil AC. Como elaborar projetos de pesquisa. $4^{\mathrm{a}}$ ed. São Paulo: Atlas; 2007.

8. Lèfevre F, Lèfevre AMC. Depoimentos e discursos: uma proposta de análise em pesquisa social. Brasília: Líber Livro; 2005.

9. Ministério da Saúde (BR). Conselho Nacional de Saúde. Resolução $n^{\circ} 196$, de 10 de outubro de 1996. Aprova diretrizes e normas regulamentadoras de pesquisa envolvendo seres humanos. Brasília: Ministério da Saúde; 1996.

10. Brito RS, Santos DLA, Maciel PSO. Olhar masculino acerca do atendimento na estratégia saúde da família. Rev Rene. 2010;11(4):135-42.

11. Teles LMR, Silva SS, Eduardo KGT, Moura ERF, Damasceno AKC. Atenção em anticoncepção oferecida por equipe de PSF em São Gonçalo do Amarante - CE. Rev Eletrônica Enferm [Internet]. 2010 [acesso em 2011 ago 24];12(4):711-8. Disponível em: http://www.fen.ufg.br/revista/v12/n4/v12n4a17.htm.

12. Santos JC, Freitas PM. Planejamento familiar na perspectiva do desenvolvimento. Ciênc Saúde Coletiva. 2011;16(3):1813-20.

13. Gontijo DT, Bechara AMD, Medeiros M, Alves HC. Pai é aquele que está sempre presente: significados atribuídos por adolescentes à experiência da paternidade. Rev Eletrônica Enferm [Internet]. 2011 [acesso em 2011 ago 24];13(3):439-48. Disponível em: http://www.fen.ufg.br/fen_revista/v13/n3/pdf/v13n3a09.pdf.

14. Silva RM, Araújo KNC, Bastos LAC, Moura ERF. Planejamento familiar: significado para mulheres em idade reprodutiva. Ciênc Saúde Coletiva. 2011;16(5):2415-24.

15. Ribeiro PJ, Barros KHS, Reis RA, Campinas LLSL. Planejamento familiar: importância do conhecimento das características da clientela para implementação de ações de saúde. Mundo Saúde. 2008;32(4):412-9.

16. Sauthier M, Gomes MLB. Gênero e planejamento familiar: uma abordagem ética sobre o compromisso profissional para a integração do homem. Rev Bras Enferm. 2011;64(3):45764. 


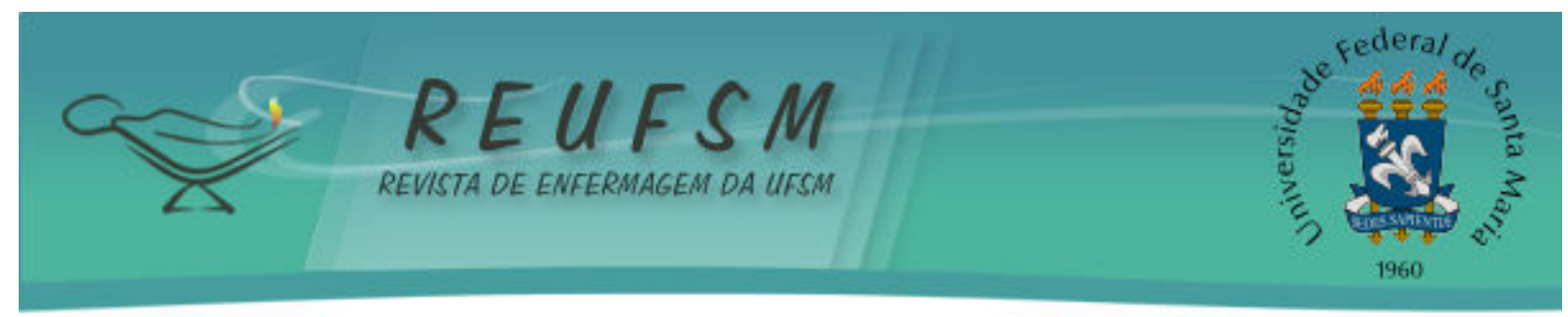

17. Albuquerque GA, Villela WV. Uso do preservativo feminino como método contraceptivo: experiências de mulheres em uma unidade básica de saúde no município de Juazeiro do Norte - CE. Rev APS. 2011;14(2):185-96.

18. Portella AP, Bezerra MS, Ferreira V, Ávila MB, Albuquerque RM. Contracepção e planejamento reprodutivo na percepção de usuárias do Sistema Único de Saúde em Pernambuco. In: Miranda-Ribeiro P, Simão AB, organizadores. Demografia em debate. Belo Horizonte: ABEP, UNFPA; 2008. v.2, p. 119-39.

19. Moreira KAP, Costa AAR, Araújo MAM, Queiroz MVO. Causas e características da resistência à vasectomia em homens. Rev RENE. 2008;9(2):82-9.

20. Prates CS, Abib GMC, Oliveira DLLC. Poder de gênero, pobreza e anticoncepção: vivências de multíparas. Rev Gaúcha Enferm. 2008;29(4):604-11.

21. Afonso RR, Lemos A. Adesão nos grupos educativos em contracepção em uma área programática no Rio de Janeiro. Rev Enferm Cent -Oeste Min. 2011;1(2):238-47.

22. Julião GG, Weigelt LD. Atenção à saúde do homem em unidades de estratégia de saúde da família. Rev Enferm UFSM [Internet]. 2011 [acesso em 2013 jul 18];1(2):144-52. Disponível em: http://cascavel.ufsm.br/revistas/ojs-

2.2.2/index.php/reufsm/article/view/2400/1743.

Data de recebimento: $18 / 07 / 2013$

Data de aceite: 09/07/2014

Contato com autor responsável: Glauberto da Silva Quirino

Endereço postal: Rua Manuel Miguel Cordeiro, 109, José Geraldo da Cruz, CEP 63033-265, Juazeiro do Norte-CE

E-mail: glauberto.quirino@urca.br 